\title{
NINA RODRIGUES, GILBERTO FREYRE E FLORESTAN FERNANDES: TRÊS PERSPECTIVAS DISTINTAS SOBRE A MISCIGENAÇÃO
}

\author{
NINA RODRIGUES, GILBERTO FREYRE AND FLORESTAN FERNANDES: THREE \\ DIFFERENT PERSPECTIVES ON MISCIGENATION
}

Vanessa Florêncio de OLIVEIRA ${ }^{1}$

RESUMO: O trabalho pretende comparar as análises feitas por Nina Rodrigues, Gilberto Freyre e Florestan Fernandes sobre as questões relativas à população negra no Brasil. Desse modo, Nina Rodrigues situado no contexto da abolição encontrava na miscigenação entre negros e brancos um problema que atrasava o caminho rumo a uma sociedade civilizada, diferente de Gilberto Freyre que encontrava na miscigenação a particularidade que caracteriza o povo brasileiro. Florestan Fernandes por outro lado, sob outras perspectivas presentes na década de 1950, entendia que os obstáculos pelos quais passavam as populações negras eram de ordem social. Nesse sentido, o trabalho procurar apreender as principais concepções desses intelectuais preocupados com os resultados da miscigenação efetiva da sociedade brasileira após a abolição.

PALAVRAS-CHAVE: Miscigenação. Populações negras. Nina Rodrigues. Gilberto Freyre. Florestan Fernandes.

ABSTRACT: The paper intends to compare the analyzes made by Nina Rodrigues, Gilberto Freyre and Florestan Fernandes on the issues concerning the black population in Brazil. Thus, Nina Rodrigues in the context of the abolition found in the miscegenation between blacks and whites a problem that delayed the way towards a civilized society, different from Gilberto Freyre that found in miscegenation the particularity that characterized the Brazilian people. Florestan Fernandes, on the other hand, under other perceptions present in the 1950s, understood that the obstacles that the black populations passed were social. In this sense, the work seeks to apprehend the main conceptions of these intellectuals concerned with the results of the effective miscegenation of Brazilian society after the abolition

KEYWORDS: Miscegenation. Black populations. Nina Rodrigues. Gilberto Freyre. Florestan Fernandes.

\section{Introdução}

O trabalho pretende fazer algumas breves comparações das análises de Nina Rodrigues, Gilberto Freyre e Florestan Fernandes sobre as questões étnico-raciais no Brasil.

${ }^{1}$ Universidade Estadual Paulista (Unesp), Faculdade de Ciências e Letras, Araraquara - SP - Brasil. Graduanda em Ciências Sociais. E-mail: vanessafoliver@hotmail.com. 
A produção intelectual de Nina Rodrigues encontra-se entre o final do século XIX e o início do século XX, período em que o Brasil passava por grandes transformações políticas, principalmente decorrentes da abolição e da proclamação da república. Nesse contexto uma questão se colocava para Nina Rodrigues e tantos outros intelectuais de sua época preocupados com o Estado-nação a ser construído. Como resolver o problema do Brasil mestiço? Como fazer dar certo um país tão heterogêneo? Para Nina Rodrigues o problema que o Brasil teria que enfrentar era a incapacidade do negro de construir uma civilização, em função do seu atraso físico e mental.

No livro Os Africanos no Brasil, Nina Rodrigues destaca logo no primeiro capítulo a diferença entre a condição da população negra na América latina e as condições dessas populações nos Estados Unidos. Se nos Estados Unidos o cruzamento entre negros e brancos é evitado, no Brasil ele "[...] incorporou-se à população local no mais amplo e franco mestiçamento.” (RODRIGUES, 1988, p. 13).

Para Rodrigues "o problema brasileiro" seria a mestiçagem. A mistura entre negros e brancos constituiria um povo degenerado, isso porque Rodrigues acreditava que o negro estava em um estágio evolutivo inferior ao do homem branco, sendo impossível que o encontro dessas duas "raças" pudesse formar uma sociedade mais homogênea.

Na tese de doutorado As Ilusões da Liberdade de Mariza Corrêa, a autora ressalta que "Nina Rodrigues é bem um testemunho de seu tempo, que é também preciso entender para compreendê-lo." (CORRÊA, 2013, p.64).

Assim, como Rodrigues, médicos da época e intelectuais de outros segmentos que atuavam nas academias e por vezes na vida social e política do país, recebiam fortemente na segunda metade do século XIX as teorias importadas da Europa como o darwinismo social, bem como a influência da antropologia criminal, está última desenvolvida pelo médico italiano Lombroso Cesare, figura muito influente na constituição e no desenvolvimento das pesquisas de Nina Rodrigues no Brasil.

Sua admiração pelos principais teóricos do grupo da antropologia criminal italiana e pelos da escola médico-legal francesa permaneceu inalterada, ainda que se considere discutível a aplicação de alguns de seus postulados no cenário brasileiro, e não há dúvidas de que o trabalho deles serviu de exemplo a atividade que desenvolveu na Bahia. (CORRÊA, 2013 p. 68).

Com todas essas referências, Rodrigues desenvolveu sua pesquisa sobre um minucioso trabalho de campo, construindo um método etnográfico e dando sentido a uma nova ciência no Brasil, a antropologia urbana. 
Participou de manifestações religiosas como o terreiro (prática comum entre os negros da Bahia) e através de suas pesquisas sobre as populações negras desvelou as etnias africanas que foram traficadas para o Brasil, chegando à conclusão, ao longo do seu trabalho de campo, de que havia superioridade, cultural e social até mesmo entre essas etnias. Segundo Rodrigues, em Os Africanos no Brasil os grupos Bantos, por exemplo, seriam inferiores tecnologicamente, linguísticamente e culturalmente a outras etnias, como as de Nigéria e Benim.

Assim, como os africanos eram diferentes entre si para Rodrigues, eles também eram diferentes e inferiores aos homens brancos, estando em estágios distintos de evolução.

Para Nina Rodrigues, o negro era um problema que a sociedade brasileira teria que enfrentar se quisesse um projeto de futuro próspero e a abolição e a proclamação da república não homogeneizaram uma sociedade de contrastes do ponto de vista cultural social e biológico.

\section{Se para Nina Rodrigues a mestiçagem era um problema para Gilberto Freyre era a "solução"}

A obra de Nina Rodrigues e a de Gilberto Freyre estavam separadas por um curto espaço de tempo. Apesar disso, suas análises tinham bases em escolas distintas que lhes permitiram trabalhar com determinado viés sobre as questões que envolviam a mestiçagem.

Em 1930 o debate sobre a miscigenação continuava presente, no entanto nesse período muitas das questões levantadas por teóricos do final do século XIX começavam a "cair por terra", com as descobertas científicas mais recentes abria se um leque maior para se pensar a miscigenação na sociedade brasileira.

Gilberto Freyre não deixa de reconhecer as contribuições que Nina Rodrigues trouxe para o campo da ciência, principalmente sobre os povos Africanos que foram traficados para o Brasil. No entanto, suas experiências com a antropologia americana de Franz Boas, possibilitaram ao sociólogo a pensar as questões que envolvem o negro através do culturalismo. Em outras palavras, as noções de raça ligadas à biologia não eram o enfoque de Gilberto Freyre sobre negros e mestiços.

O autor observa a miscigenação por uma ótica que difere da maioria dos intelectuais de sua época, sendo a miscigenação a característica que nos dá unidade. Longe do segregacionismo em que se encontravam as populações negras nos Estados Unidos, fato que 
Nina Rodrigues já havia observado no Brasil, pois a mistura entre brancos, negros e indígenas havia ido além da herança genética.

Todo brasileiro, mesmo o alvo, de cabelo loiro, traz na alma, quando não na alma e no corpo - a muita gente de jenipapo ou mancha mongólica pelo Brasil - a sombra, ou pelo menos a pinta, do indígena ou do negro. No litoral, do Maranhão ao Rio Grande do Sul, e em Minas Gerais, principalmente do negro. A influência direta, ou vaga e remota, do Africano. (FREYRE, 2003, p. 367).

Para a historiadora Lilia Schwarcz e André Botelho (2009), Gilberto Freyre ao declarar no clássico Casa Grande \& Senzala a forte influência africana no Brasil, não teria negado os antagonismos que se constituíram no interior da sociedade brasileira. Todavia, acreditava que a relação entre negros e brancos convergia para uma convivência menos conflituosa, se comparadas às dos Estados Unidos, por exemplo.

Longe de ter se tornado uma sociedade mais igualitária, muitas das bases racistas continuavam presentes na sociedade brasileira, claro que com um novo verniz no contexto em que Gilberto Freyre escreve. Sob uma nova ótica, o autor pernambucano acreditava que seríamos um país mestiço desde o início da colonização, pois a gênesis da nossa sociedade já seria um encontro.

\footnotetext{
A singular pré-disposição do português para colonização híbrida e escravocrata dos trópicos explica-a em grande parte seu passado étnico, ou antes cultural, de povo indefinido entre a Europa e a África. Nem intransigentemente de uma nem da outra, mas das duas. (FREYRE, 2003, p. $66)$.
}

Diversamente das proposições sobre a mestiçagem propagadas no final do século XIX - de que a mistura de raças teria sido um verdadeiro atraso para a construção da sociedade brasileira - Gilberto Freyre acredita que a mestiçagem foi o que fez os portugueses triunfar sobre a colonização em detrimento de outros colonizadores europeus.

A mistura das raças não seria como em Nina Rodrigues degenerativa, mas ao contrário a miscigenação "[...] foi para os portugueses vantagem na sua obra de conquista de colonização dos trópicos. Vantagem para sua melhor adaptação, se não biológica, social." (FREYRE, 2003, p. 75).

\section{Para Florestan Fernandes o debate é sobre classe}


As implicações dos debates iniciados por Gilberto Freyre no seu livro Casa Grande \& Senzala sobre a miscigenação no Brasil e uma possível convivência pacífica entre brancos e negros, trouxe posteriormente muitas críticas a sua obra. Isso porque, um grupo de jovens pesquisadores liderados por Florestan Fernandes através de pesquisas realizadas sobre as populações negras constatam que a convivência entre brancos e negros no país nunca deixou de ser conflituosa e extremamente desigual.

\begin{abstract}
Estes cientistas acumularam uma nova quantidade de evidências de que os brancos no Brasil foram preconceituosos e de que os negros, apesar de não terem sido legalmente discriminados, foram "natural" e informalmente segregados. A maioria da população negra permaneceu numa posição subalterna sem nenhuma chance de ascender na escala social. As possibilidades de mobilidade social foram severamente limitadas aos negros e sempre que eles competiram com os brancos foram discriminados. (COSTA, 1999, p. 366).
\end{abstract}

Nesse trecho do livro Da Monarquia à República: momentos decisivos, da historiadora Emília Viotti da Costa (1999), fica claro que o debate sobre raça não está mais em questão para esse grupo de pesquisadores dos anos 1950 que faziam parte da Escola de São Paulo. Assim a principal questão era saber como lidar com o antagonismo social em que se encontravam os negros em relação aos brancos, em todos os âmbitos da sociedade brasileira, especialmente nos espaços urbanos. Sendo assim, Florestan Fernandes analisou as questões que envolviam o negro na sociedade brasileira pela ótica estrutural funcionalista, ou seja, através de uma perspectiva de classe.

Florestan Fernandes escreve uma obra importante intitulada $A$ integração do negro na sociedade de classes (2008), onde demonstra a dificuldade do negro de se integrar em uma sociedade industrial, pois a maior parte dessa população se encontrava no campo ou exercendo serviços domésticos e com o fim da escravidão não houve nenhum projeto de socialização para a integração desses homens e mulheres negras.

Elide Rugai Bastos destaca em uma coletânea de ensaios sobre Fernandes intitulada A Questão Racial e a Revolução Burguesa (1987), que o maior problema após a abolição foi a ausência de um processo de ressocialização do negro para a nova ordem estabelecida. Dessa forma, o negro foi impossibilitado de ascender socialmente e de se inserir na ordem competitiva da sociedade de classes.

Para Fernandes a marginalização do negro não podia ser resolvida sob um debate de "raça”, pois a questão da pobreza dessa população só se resolveria através da sua integração 
na sociedade. Dessa maneira, Fernandes acreditava que o racismo é um dado cultural que só pode ser superado pela classe.

\section{Considerações finais}

Assim como Fernandes trabalhou sobre a ótica da cidade de São Paulo, Gilberto e Rodrigues trabalharam com perspectivas de espaços distintos, o que nos leva a compreender de certo modo, quais as relações que se estabeleciam em cada local e tempo sobre o povo negro com o advento da abolição.

Nina Rodrigues - que se encontrava no contexto recente ao fim da escravidão estava preocupado com o futuro do país, afinal na sua concepção a mistura entre homens brancos e negros provocaria uma degenerescência na população. Pois esse autor entendia que o negro era inferior ao homem branco por natureza, estaria ele em um estágio anterior ao dos "homens civilizados".

Diferente de Rodrigues, Gilberto Freyre se encontrava em um período onde novas escolas como a de Franz Boas davam margem para pensar o negro através do ponto de vista culturalista. Diferente de Rodrigues para Freyre o mestiço não era um homem degenerado, mas sim nosso ponto de unidade, não apenas genética, mas cultural e psíquica. E mesmo com todo conflito presente na sociedade brasileira, gerada pela escravização do negro, Freyre em um movimento paradoxo, abre espaço para falar sobre a possível convivência entre brancos e negros, "apaziguamento" esse, que se daria principalmente em espaços domésticos, de convivência mais íntima entre negros e brancos.

Discordando dos dois autores, Florestan Fernandes encara a marginalização da população negra/mestiça como um problema que só pode ser solucionado com o fim da pobreza e a socialização dessa população nos grandes centros urbanos. Para o sociólogo paulista, o debate sobre "raça" não melhora a condição do negro na sociedade de classes, sendo esse debate já ultrapassado.

Florestan Fernandes também critica as teorias de Freyre em relação ao mestiçamento da população ter gerado de alguma maneira uma "pacificação" entre brancos e negros no país, já que as pesquisas realizadas em 1950 contestam a tese da mestiçagem.

\section{REFERÊNCIAS}

BASTOS, E. R. A questão racial e a revolução burguesa. In: D'INCAO, M. A. (Org.). O saber militante: ensaios sobre Florestan Fernandes. Rio de Janeiro: Paz e Terra, 1987. p.140-150. 
BOTELHO, A. B.; SCHWARCZ, L. M. (Org.). Um enigma chamado Brasil. São Paulo: Cia. de Letras, 2009.

COSTA, E. V. da. Da Monarquia a República: momentos decisivos. 6.ed. São Paulo: Fundação Ed. da UNESP, 1999.

CORRÊA, M. As ilusões da liberdade: a Escola Nina Rodrigues e a antropologia no Brasil. 3.ed. Rio de Janeiro: Ed. da Fiocruz, 2013.

FERNANDES. F. A integração do negro na Sociedade de Classes. São Paulo. 5.ed. São Paulo: Globo, 2008.

FREYRE, G. Casa Grande \& Senzala. 48.ed. São Paulo: Global, 2003.

RODRIGUES, N. Os africanos no Brasil. 7.ed. São Paulo: Ed. da UNB, 1988.

\section{Como referenciar este artigo}

OLIVEIRA, Vanessa Florêncio de. Nina Rodrigues, Gilberto Freyre e Florestan Fernandes: três perspectivas distintas sobre a miscigenação. Rev. Sem Aspas, Araraquara, v.6, n.1, p. 8591, jan./jun. 2017. e-ISSN 2358-4238.

Submetido em: 20/04/2017

Aprovado em: 26/05/2017 